CHAPTER 8:

\title{
Reflections on the IEA International Computer and Information Literacy Study 2018
}

In this chapter we reflect on the contribution of the International Computer and Information Literacy Study (ICILS) to understanding the extent to which young people are able to use information and communication technology (ICT) productively for a range of purposes. Those purposes relate to what happens in school and in other environments such as home, society, and future workplaces. In addition, we provide perspectives on factors that are associated with development of the digital capacities of young people. We provide an overview of the main themes emerging from the analyses presented in this report. Within each theme, we reflect on the implications of these results for developments in policy and practice that support the teaching and learning of ICT-related competencies in schools.

\section{ICILS as a pioneering study}

ICILS 2013 was the first cycle of the study. It established an agreed definition and explication of computer and information literacy $(\mathrm{CI})$ as a student learning outcome. Furthermore, it operationalized a standardized approach to the measurement of CIL in an international largescale assessment (ILSA), and established measures of CIL that could be used to monitor and investigate a critical aspect of students' digital competence.

ICILS 2018 has extended the work of ICILS 2013 in investigating grade 8 students' capacities to use ICT productively for a range of purposes, including those that go beyond a basic use of computers. ICILS 2018 updated the digital contexts for the measurement of students' CIL and investigated in greater detail the nature of classroom teaching activities associated with the development of CIL. In addition, it developed and implemented an objective assessment of computational thinking (CT). While concepts associated with CT have been recognized since the advent of computing as a field of study in the 1940s (Denning 2017), the role of CT in curricula has waxed and waned since the introduction of personal computers in schools in the final quarter of the twentieth century. In recent years, there has been a resurgence of interest in the teaching and learning of CT as both a foundation for the effective use of digital technologies and as a transferable set of problem solving skills. ICILS 2018 included an option for countries to collect objective data measuring students' capacities to plan and operationalize computer-based solutions to real-world problems. ICILS 2018 established both a framework for measuring and reporting achievement in $\mathrm{CT}$ and baseline measures against which $\mathrm{CT}$ can be monitored over time. ICILS remains at the forefront of innovation in the measurement and research of digital literacy related competences in ILSA.

\section{The nature of CIL and CT \\ Describing CIL}

CIL refers to an "individual's ability to use computers to investigate, create, and communicate in order to participate effectively at home, at school, in the workplace, and in society" (Fraillon et al. 2013, p. 17). In ICILS, there is an emphasis on students' abilities to use computer technologies to collect and manage information and to produce and exchange information.

The CIL achievement scale was established with a midpoint (average) of 500 and with 100 scale points as one standard deviation of achievement across ICILS 2013 countries. Theoretically, the scale is "unbounded" at the top and bottom allowing for the measurement and description of extremely high and low CIL achievement. The scale has been described using four levels of achievement. Each level spans 85 scale points and the described levels of the scale range from Level 1 (from 407 to 491 scale points) to Level 4 (above 661 scale points). The levels were 
established such that when a student's achievement is reported to be within a given level, we can be confident that the level describes the CIL that can be demonstrated by the student, even if the student's CIL scale score is near the bottom of the level. Students within any given level can be assumed to have mastered content at lower levels.

Students working at Level 1 (from 407 to 491 scale points) demonstrate familiarity with the basic range of software commands that enable them to access files and complete routine text and layout editing under instruction. They recognize not only some basic conventions used by electronic communications software, including knowing which communication tool to use in a given context, but also the potential for misuse of computers by unauthorized users.

Students working at Level 2 (from 492 to 576 scale points) demonstrate basic use of computers as information resources. They are able to locate explicit information in simple digital resources, select and add content to information products, and exercise some control over laying out and formatting text and images in information products. They can explain the advantage of using a given communication tool in a given context and demonstrate awareness of the need to protect access to some electronic information and of possible consequences of unwanted access to information.

Students working at Level 3 (from 577 to 661 scale points) possess sufficient knowledge, skills, and understanding to independently search for and locate information. They also have the ability to edit and create information products. They can select relevant information from within electronic resources, and the information products they create exhibit their capacity to control layout and design. Furthermore, students working at Level 3 demonstrate awareness that the information they access may be biased, inaccurate, or unreliable. They also can evaluate the weaknesses of the use of a given communication tool in a given context.

Students working at Level 4 (above 661 scale points) execute control and evaluative judgment when searching for information and creating information products. They also demonstrate awareness of audience and purpose when searching for information, selecting information to include in information products, and formatting and laying out the information products they create. Students working at Level 4 additionally demonstrate awareness of the potential for information to be a commercial and malleable commodity and apply the conventions of a given communication tool in a given context to support inclusivity.

\section{Describing CT}

In ICILS 2018, CT is defined as "an individual's ability to recognize aspects of real-world problems which are appropriate for computational formulation and to evaluate and develop algorithmic solutions to those problems so that the solutions could be operationalized with a computer" (Fraillon et al. 2019, p. 27). In ICILS there is an emphasis in CT on students' abilities to conceptualize problems, plan and evaluate solutions, and to operationalize solutions using algorithms and simple computer code.

The ICILS 2018 assessment of CT is the first time that an objective assessment of CT has been created and used in data collection in an ILSA. Data collected in 2018 were used to establish the CT achievement scale. The scale was centered around a midpoint of 500 (determined using the average achievement of the ICILS 2018 countries participating in the CT assessment) and with 100 scale points representing one standard deviation of achievement across the ICILS 2018 countries that participated in the CT assessment.

The CT scale has been described according to three regions of achievement. The primary purpose of these regions is to describe the increase in complexity of CT knowledge, skills, and understandings from low to high achievement in order to understand learning progress in this newly defined area. 
Students showing achievement corresponding to the lower region of the scale demonstrate familiarity with the basic conventions of digital systems to configure inputs, observe events, and record observations when planning computational solutions to given problems. When developing solutions in the form of algorithms, they can use a linear (step by step) sequence of instructions to meet task objectives.

Students showing achievement corresponding to the middle region of the scale demonstrate understanding of how computation can be used to solve real-world problems. They can plan and execute systematic interactions with a system so that they can interpret the output or behavior of the system. When developing algorithms, they use repeat statements effectively.

Students showing achievement corresponding to the upper region of the scale demonstrate an understanding of computation as a generalizable problem-solving framework. They can explain how they have executed a systematic approach when using computation to solve real-world problems. Furthermore, students operating within the upper region can develop algorithms that use repeat statements together with conditional statements effectively.

\section{$\mathrm{CIL}$ and $\mathrm{CT}$ achievements vary greatly within countries}

There were large variations that existed in student CIL and CT proficiency within countries. We will address variations in CIL and CT in turn.

\section{Variations in CIL}

In ICILS 2018, the average CIL achievement of students across countries varied from 395 scale points to 553 scale points, which spans from Below Level 1 to within Level 3 (Table 3.4). Of particular interest in ICILS were the variations in CIL achievement within countries. Even within the countries with higher average CIL achievement there were many students who were able to demonstrate only the basic functional skills described in CIL Level 1. Students working at this level can for example:

- Identify who receives an email by carbon copy (CC);

- Identify problems that can result from mass messaging;

- Record key points from a video into a text-based note taking application;

- Use software to crop an image;

- Place a title in a prominent position on a webpage;

- Create a suitable title for a slide show;

- Insert an image into a document; and

- Suggest one or more risks of failing to log out from a user account when using a publicly accessible computer.

In ICILS 2018 more than one quarter of students in all but one country and one benchmarking participant were performing at Level 1 or Below Level 1. In five countries, the proportion was more than one half (Table 3.5). So regardless of variations in CIL achievement across countries, there remained large numbers of students who were able to complete only the most basic functional tasks on a computer.

With this in mind, across all countries there were students who were achieving at the higher levels on the CIL scale. In three countries and one benchmarking participant more than one quarter of students were performing at Level 3 or above (Table 3.5). As a minimum these students are able to, for example:

- Identify when content published on the internet may be biased as a result of a publisher's content guidelines or advertising revenue directing content; 
- Select relevant information according to given criteria to include in a website;

- Know what information is useful to include when recording a source of information from the internet;

- Use generic online mapping software to represent text information as a map route;

- Select an appropriate website navigation structure for given content;

- Select and adapt some relevant information from given sources when creating a poster;

- Demonstrate control of color and contrast to support readability of a poster; and

- Demonstrate control of text layout when creating a presentation.

While variations in CIL existed across countries, the variation within countries was large. Within each ICILS 2018 country or benchmarking participant the difference in achievement between the top five percent of students and the bottom five percent of students was more than 200 scale points (Table 3.4). This within country difference is larger than the difference in mean CIL achievement between the highest and lowest achieving countries. The existence of these large variations in achievement within countries and the proportions of students demonstrating only the most basic CIL skills suggest that acquisition of these skills cannot be left to incidental learning.

In ICILS 2013, we questioned the relevance of the description of the current generation of young people as digital natives. The ICILS 2018 data again support the contention that, regardless of our own impressions of the facility with which young people embrace new technologies, there remain large proportions of young people who can complete only the most basic technical operations when using a computer. One danger of assuming that young people are imbued with a capacity to manage complex functions on computers is that we may infer that there is little need to formally address knowledge, skills, and understandings as part of schooling. The ICILS 2018 data support the findings of ICILS 2013 in demonstrating that many grade 8 students have developed little more than rudimentary CIL capacities. Formal schooling needs to play a more significant role in developing these capacities within young people given that it is clear that, for many students, they are not currently being developed through other means.

\section{Variations in CT}

In ICILS 2018, the average CT of students across countries varied by 76 scale points, from 460 to 536 scale points, all of which are in the middle region of the scale. However, within countries there was considerable variation in student CT. In all countries the difference in CT between the top and the bottom five percent of students was greater than 250 scale points, more than three times the difference between the highest and lowest average CT across countries (Table 4.1).

In all but two countries more than one quarter of students' $\mathrm{CT}$ scores were less than 459 scale points. This is described as CT achievement in the lower region of the CT scale. These students were, at most, able to:

- Create a complete but suboptimal route from one location to another on a network diagram;

- Partially debug an algorithm that uses a repeat statement by correcting the logic of connected statements;

- Create an efficient algorithm that meets all of the given task objectives for a low-complexity problem (i.e., a problem with a limited set of available commands and objectives); and

- Create an inefficient algorithm that meets all of the given task objectives for a mediumcomplexity problem (e.g., a problem with multiple objectives best solved using a repeat statement). 
As was reported for CIL achievement, regardless of variations in achievement across countries, there were large proportions of students who are able to complete only the most basic CTrelated tasks. Where tasks were more complex, such as those with simple iterative logic or with multiple solutions, these students would typically provide incomplete or inefficient solutions.

Across countries, between two and 16 percent of students had CT achievement scores of more than 639 scale points, or in the upper region of the scale. These students were likely to be able to:

- Explain the value of a digital system for real-world problem solving;

- Complete a simple decision tree with the correct use of both logic and syntax;

- Debug, with the most efficient solution, an algorithm for a high-complexity problem (e.g., a problem with multiple task objectives best solved using repeat and conditional statements); and

- Create an efficient algorithm that meets all of the objectives for a high-complexity problem (e.g., multiple task objectives best solved using repeat and conditional statements).

It is encouraging to note that some students, albeit in relatively small proportions, demonstrated understandings of the use of digital systems in real-world problem solving and were able to create efficient algorithms expressed as visual code commands. The broad range of student CT achievement within countries shows that these skills can be developed by grade 8 students but suggests that these skills may not be developed through exposure to and use of digital devices alone. In Chapter 2, we reported considerable variation across countries regarding their national curriculum emphases on CT although most countries do provide a separate CIL-related subject that includes at least some coding. There is opportunity across countries to increase the emphasis on the core aspects of CT in curriculum and learning programs.

\section{CIL, CT, digital literacy, and student gender}

In ICILS 2018 CIL and CT are conceptualized, operationalized, measured, and reported as separate areas of learning. The two domains are clearly discrete in their focus. CIL emphasizes information literacy in receptive and productive communicative contexts, whereas CT emphasizes problem specification and the creation of solutions that can be implemented by computers. Despite the obvious conceptual and operational differences, it is clear that the two domains are practically linked because both involve interaction with digital devices. At a conceptual level, the domains are both rooted in an understanding of how computers process the information we provide them, how they are used as tools, and the conventions associated with computer use and software environments.

These two ICILS domains can be regarded as complementary aspects of a broader notion of digital competence. However, the complementarity of the two domains and their contribution to a larger notion of digital competence remains a question for further investigation. For example, the CIL content in ICILS can be seen to relate to each of the five competence areas (information and data literacy; communication and collaboration; digital content creation; safety; and problem solving) described in the European Commission's DigComp 2.0 Framework (Vuorikari et al. 2016). The ICILS CT content domain can be regarded as particularly relevant to the DigComp problem-solving competence area. While it is possible to see how the two ICILS achievement domains can be considered under an example of a broader notion of digital competence, the Computational Thinking Study under the EU Science Hub, lists the relationship between CT and digital literacy/digital competence as one of the areas in which more evidence-based research is needed (European Commission 2019). ICILS 2018 data and data to be obtained from future cycles of ICILS may contribute to better understanding of this connection. Under an alternative approach, the US National Assessment of Educational Progress Technology and Engineering 
Literacy assessment includes content that overlaps with each of CIL and CT although without the same emphasis on CT as a form of problem solving processes (see, NAGB [National Assessment Government Board] 2014).

ICILS 2018 has provided empirical data that contributes to our understanding of the relationship between CIL and CT. Achievement in the two domains were highly correlated. Across ICILS countries that participated in CIL and CT the correlation in achievement ranged from 0.74 to 0.89. The high correlation between CIL and CT may be explained, in part, by the relationship of achievement in each domain to general academic ability. However, despite the strong association between CIL and CT achievement, data from ICILS 2018 show different patterns of achievement in each of CIL and CT by student gender. Female students showed consistently higher CIL achievement than male students, and male students tended to demonstrate higher CT achievement than female students.

If one accepts the proposition that CIL achievement relates to information literacy in a general ICT context and CT achievement relates more to specialized ICT use, then the difference in the association between each of CIL and CT and student gender is consistent with the patterns of gender difference in students' uses of and attitudes towards the use of ICT. Female students tended to report using ICT for school-related purposes and using general ICT applications slightly more than male students. Where differences occur, female students tended to report learning more about CIL-related content at school than did male students and overall there was little reported difference in students' general ICT self-efficacy. However, male students reported more than female students that they were learning about CT-related content at school. Male students also reported consistently higher ICT self-efficacy regarding specialist ICT tasks, generally more positive perceptions about the role of ICT in society, and generally less negative perceptions about the role of ICT in society.

The ICILS 2018 data regarding CIL, CT, and student gender are consistent with current beliefs about the differences in female and male students' attitudes towards and uses of ICT. Female students are stronger users of ICT for general school-related tasks (such as locating information from within digital sources and creating digital artefacts to communicate information to others). Male students are more confident to approach, and slightly stronger at dealing with, specialist ICT tasks (such as changing computer settings or creating programs). These findings provide a challenge to curricular and educational policy. If CIL and CT are valued by policymakers as components of a broader digital literacy necessary for effective participation in an increasingly digital world, then ICILS 2018 raises questions about how these gender differences in attitudes and achievement may be addressed.

\section{Evidence of the digital divide}

The notion of a digital divide is, at its simplest, a reference to the varying opportunities and access that people have to ICT. Hohlfeld et al. (2008) postulated a model for researching the digital divide in schools, which can be considered to have three levels: access to technological infrastructure; the use of technology in the classroom; and the use of technology to empower individuals. While ICILS 2018 was not designed with a particular model of the digital divide in mind, for the purpose of this discussion we accept the proposition that consideration of the digital divide can extend beyond access to technology to include how technology is used in schools and how students are empowered through technology to participate in their digital world.

Twelve of the 14 ICILS 2018 countries and benchmarking participants indicated that reducing the digital divide between groups of students was emphasized in their plans, policies, and priorities regarding the use of ICT (see Chapter 2). In ICILS 2018, the relationships between student socioeconomic status (SES) and CIL and CT were consistent and clear. Across ICILS countries student SES (both for individual students and averaged within their schools) was a strong 
predictor of student CIL and CT. Other consistent predictors were students' experience of using computers and their frequency of using ICT at home (Tables 3.8, 3.10, 4.3, 4.5, 7.5, and 7.10).

While the relationship between student SES and educational achievement is a consistent and pervasive finding in ILSA studies across all learning areas, in ICILS the relationship of SES to CIL and CT appears to involve a combination of factors. The generally observed outcome of SESrelated educational advantage or disadvantage combines with the specific SES-related influences relating to the digital divide. Students from low SES backgrounds may have limited access to ICT infrastructure and the educational benefits associated with its use in learning about CIL and CT.

It is beyond the scope of this report to investigate in detail the nature and effect of the digital divide within and across individual ICILS countries. However, evidence of a digital divide is clearly apparent in the student achievement results in both CIL and CT. This finding alone warrants consideration about how countries may work to reduce the divide. The ICILS data offer the potential to examine evidence of a digital divide within countries, not just in terms of infrastructure provision and access to ICT but to probe differences in approaches to the teaching and learning of CIL and CT in schools. The ICILS teacher and school-level data offer a resource to be investigated from this perspective.

\section{Digital devices as digital textbooks}

ICILS 2013 called into question "the idealized images commonly associated with visions of ICT in teaching and learning" (Fraillon et al. 2014, p. 257). One of these images related to the degree to which digital technologies were being used to transform classrooms from traditional teacher-centered environments into more constructivist learning environments. In ICILS 2013, we found that the most commonly reported uses of computers in classes by students related to tasks associated with document preparation and presentations. The activities reported most frequently by teachers related to presenting information to students and skills development through repetition. The conclusion in 2013 was that "computers were most commonly being used to access digital textbooks and workbooks rather than to provide dynamic, interactive pedagogical tools" (Fraillon et al. 2014, p. 257).

In ICILS 2018 we again sought to investigate the ways in which students and teachers perceived the use of ICT in teaching and learning. As the countries that participated in ICILS 2018 are largely different to those that participated in ICILS 2013, we will not discuss changes within countries, rather we will discuss the findings of ICILS 2018 (reported in detail in Chapters 5 and 6) as a snapshot of ICT use in classes across a broad range of countries in 2018 . The context for this can be compared to that of ICILS 2013 in which a similar snapshot was made, albeit across a somewhat different but similarly broad set of countries.

In ICILS 2018 the activities using ICT applications reported most frequently by students in their lessons were using computer-based information resources, word-processing software, and presentation software. The least frequently reported activities were using simulations and modeling software, concept mapping software, and tools that capture real-world data (Table 5.17).

The general ICT utility tools reported most frequently used by teachers in most lessons were word-processor software, presentation software, computer-based information resources, and digital contents linked with textbooks. Each of these was reported, on average across countries, to be used in most lessons by more than 30 percent of teachers. In comparison, teachers reported less use of digital learning tools in class (Table 6.20). Learning management systems and interactive digital learning resources were the digital learning ICT tools reported on average across all countries by more than 20 percent of teachers to be used in most lessons. The least frequently reported digital learning tools were practice programs or apps, e-portfolios, concept mapping software, and simulations and modeling software, all of which were reported to be used in most lessons by fewer than 10 percent of teachers (Table 6.21). 
High proportions of students did, however, report having learned to a large or moderate extent a range of content and processes associated with each of CIL and CT. On average across countries, CIL-related activities were reported to have been learned about at school, to a large or moderate extent, by more than 60 percent of students (Table 5.21). Only two aspects of CT (to make flow diagrams to show the different parts of a process and to use simulations to help understand or solve real-world problems) were reported to have been learned at school, to a moderate or large extent, by fewer than 50 percent of students on average across countries (Table 5.24).

Students' reported experience of learning about CIL and CT in class was consistent with teacher reports of their emphasis on CIL- and CT-related capabilities in their classes. On average, across countries more than 60 percent of teachers reported placing some or a strong emphasis on CIL-related capabilities with the exception of to provide digital feedback on the work of others, which was emphasized by 49 percent of teachers (see Chapter 6). While CT-related capabilities were less frequently reported to be emphasized by teachers than CIL-related capabilities, more than 60 percent of teachers reported placing some or strong emphasis on six of nine CT-related capabilities with the remaining three being emphasized by fewer than 50 percent of teachers (see Chapter 6).

So, while it is positive news that teachers and students agree that CIL and CT learning are being included in classes, the picture of classroom use of ICT in ICILS 2018 is similar to that reported in ICILS 2013 (albeit in a largely different set of countries). Despite the passage of time between 2013 and 2018 and the concomitant increase in the availability of digital technology resources for teaching and learning, the observation from ICILS 2013 that computers in school education were most commonly being used as digital textbooks remains valid. For policymakers this raises a number of questions about the contrast between the messages that are frequently provided around the use of ICT in teaching and learning and the reality of classroom practice. The questions should not only relate to the reasons for, or even the detailed nature of, the mismatch between pedagogical rhetoric and classroom realities. Rather, the questions should extend to what it is reasonable to expect from classroom teachers in their use of ICT in teaching and what best practice use of ICT looks like within countries, schools, and across learning areas. Schools and teachers should not be offered unrealistic and unachievable idealized images of ICT use in classrooms. However, further work needs to be done to determine what should be presented to schools and teachers as desirable, productive, and even "best practice" in the use of ICT in teaching.

\section{Supporting teachers to use ICT in their teaching}

We can see from the data reported in Chapter 2 that the development of CIL- and CT-related competencies are valued across ICILS countries. They are emphasized within educational plans and policies and manifest in countries' commitments to providing infrastructure, professional learning support for teachers, and learning materials relating to these areas. While CIL has a greater emphasis in curriculum across countries than $\mathrm{CT}$, both are represented in the curricula of most ICILS countries. This commitment across countries to developing digital literacy related competencies brings with it the question of what the ICILS 2018 data on teaching with and about ICT (see Chapter 6) can further tell us about how teachers can best be supported to use ICT in their teaching and to facilitate student learning in CIL and CT.

\section{Provision of ICT}

Across the ICILS 2018 countries, teachers were generally well experienced with the use of ICT in their preparation and delivery of lessons and overall indicated that they were confident to use ICT in their teaching for a broad range of actions. However, despite these positive indicators, on average across all ICILS countries, fewer than half the teachers reported using ICT in their teaching every day, and in only one country was ICT use reported to be used in teaching daily 
by more than 70 percent of teachers (Table 6.1). This raises the additional question of what can be done to increase the use of ICT in teaching.

Unsurprisingly, we found that teachers were more likely to use ICT in teaching if they believed they were in a school where there were sufficient ICT resources available to them. In this case, ICT resources referred to infrastructure, technical support, time to plan lessons, and having the opportunity to develop expertise in ICT (Table 6.10 and 6.13). It is interesting to note that teachers perceived the practical support associated with the provision of time and opportunity to develop skills as congruent with the provision of ICT infrastructure. This suggests that, while the provision of ICT infrastructure in schools can impact on the likelihood of teachers using ICT, they should be accompanied with the provision of time for teachers to plan for ICT use and develop ICT skills. When developing ICT plans and policies, it may be valuable to consider teacher time and opportunities to learn as aspects of infrastructure rather than as separate aspects of policy and planning.

\section{Collaborative school environment}

In ICILS 2013 teachers' perceptions of the degree to which they were in a collaborative school environment regarding the implementation of ICT emerged as a factor relating to teachers' likelihood to emphasize CIL in their teaching. In ICILS 2018, across a largely different set of countries, teachers' perceptions of collaboration regarding the use of ICT was again an important factor in explaining teacher practice.

In ICILS 2018, while the student assessment of CT was optional for countries, the teacher questionnaire completed by all countries included a question relating to teachers' emphasis on CT-related tasks in their teaching. In all ICILS 2018 countries, teacher perceptions of collaboration regarding the use of ICT was associated with their emphasis on developing both CIL- and CTrelated outcomes in their students (Tables 6.17 and 6.19).

This finding was consistent with that of ICILS 2013. Across the two cycles of ICILS we can see that teacher responses to their perception of working in a collaborative school environment have been expressed across a broad range of countries and with reference to their teaching of CIL and CT. To this effect we can see that the findings of ICILS 2018 have confirmed and strengthened those of ICILS 2013 and should be given due attention by policymakers when planning how to support the work of teachers in schools. Teachers are providing the clear message that their implementation of CIL- and CT-related content in their teaching is advantaged by the sense that they are working in a school with a collaborative approach to the use of ICT.

\section{Nurturing confident and enthusiastic teachers}

In ICILS 2018 we found that teachers' beliefs in their own capacities to use ICT and also their beliefs about ICT are positively associated with each other and to the degree of emphasis they place on CIL and CT in their teaching. Teachers with higher ICT self-efficacy were more likely to hold more positive views about the use of ICT in teaching and less negative views about the limitations of ICT use (Table 6.7). From this we can develop an image of teachers who are confident and vigorous proponents of ICT in education in comparison to those who lack confidence and belief in the pedagogical value of ICT. Ideally, education systems would work to support the development of the former profile in their teachers.

While teacher confidence to complete tasks using ICT was generally high, this confidence did vary across countries but more importantly with age within countries. In all countries, teachers under the age of 40 expressed higher levels of ICT self-efficacy than teachers aged 40 years or older (Table 6.3). The ICILS 2018 data raise the question of whether targeted programs to support the development of ICT use by older teachers may help to redress this imbalance. 


\section{Future directions for research}

In this report, we have offered a first look at the findings from ICILS 2018, suggested themes that have emerged in 2018, and reflected on those that have persisted since ICILS 2013. The ICILS 2018 results both answer questions relating to student learning of CIL and CT and give rise to new questions. The ICILS international database is a rich resource of data collected in ICILS 2018 that can be used to support scholars to research CIL, CT, and the contexts in which they are being developed in young people. ${ }^{31}$

Opportunities exist to investigate further the measurement properties of CIL and CT and how they may be used, for example, to identify specific areas of strength or need for students or subgroups of students within and across countries. In this report we can see strong evidence of the digital divide within countries. Further research using data from ICILS 2018 could investigate the details of the digital divide, not only in terms of the ICT resources that are available to young people but also in terms of their experience of education with ICT. ICILS has also uncovered clear evidence of gender differences in student outcomes in CIL and CT and in the pattern of differences across the two. Questions remain about what this means for our collective ambitions to support all people to develop broad digital competences.

Why, for example, do female students consistently show higher CIL performance than male students and yet male students demonstrate higher levels of engagement with and generally higher achievement in the specialized ICT use associated with CT? Is this pattern consistent within all countries, are there subgroups of students within countries for whom the gender differences do not follow the pattern? What can policymakers and schools do to redress these differences? This leads to a broader set of questions associated with the nature of teaching of $\mathrm{CIL}$ and CT in schools. Further exploration of the variety of approaches to CIL and CT education across and within ICILS countries may help to answer such questions.

In ICILS we collected detailed information from teachers and students about classroom experiences with ICT and in the teaching and learning of CIL and CT. One clear theme in this report, and of ICILS 2013, was that the most frequent uses of ICT in teaching are as digital aids in the execution of somewhat "traditional" classroom practices. The ICILS 2018 data offer the opportunity for further detailed investigation of the nature, patterns, and even profiles of school and classroom practices with ICT. This extends to the influences on teachers' propensity, willingness, and confidence to use ICT in their teaching and to incorporate the teaching of aspects of CIL and CT in their classes.

There is widespread international agreement about the importance of developing digital competences such as CIL and CT in young people. ICILS 2018 has provided clear evidence that that the knowledge, skills, and understandings that comprise these competences are not developed simply through exposure to technology. They require the support of formal education. However, more work needs to be done on how these competences are learned and how they can best be taught.

A third cycle of ICILS is planned for 2023. In ICILS 2023 we plan to build on and to extend the work of ICILS 2013 and 2018. The measures of CIL and CT will continue and be extended to include a large suite of content, including content that reflects developments in digital applications and the use of digital applications between 2018 and 2023. We will investigate the contribution of process data (data collected about the way in which students complete tasks) to our understanding of CIL and CT, and update and extend the measures dealing with the contexts in which students develop CIL and CT. ICILS will continue to be at the forefront of research into students' preparedness for life in a rapidly evolving digital world.

31 The ICILS 2018 international database is to be released to the public in March 2020. 


\section{References}

Denning, P. J. (2017). Remaining trouble spots with computational thinking. Communications of the ACM, 60(6), 33-39. Retrieved from https://cacm.acm.org/magazines/2017/6/217742remainingtrouble- spots-with-computational-thinking/abstract.

European Commission. (2019). The computational thinking study [webpage]. Brussels, Belgium: European Commission, Joint Research Centre. Retrieved from https://ec.europa.eu/jrc/en/ computational-thinking.

Fraillon, J., Ainley, J., Schulz, W., Duckworth, D., \& Friedman, T. (2019). IEA International Computer and Information Literacy Study 2018 assessment framework. Cham, Switzerland: Springer. Retrieved from https://www.springer.com/gp/book/9783030193881.

Fraillon, J., Ainley, J., Schulz, W., Friedman, T., \& Gebhardt, E. (2014). Preparing for life in a digital age: The IEA International Computer and Information Literacy Study international report. Cham, Switzerland: Springer. Retrieved from https://www.springer.com/gp/book/9783319142210.

Fraillon, J., Schulz, W., \& Ainley, J. (2013). International Computer and Information Literacy Study assessment framework. Amsterdam, The Netherlands: International Association for the Evaluation of Educational Achievement (IEA). Retrieved from https://www.iea.nl/publications/assessmentframework/international-computer-and-information-literacy-study-2013.

Hohlfeld, T.N., Ritzhaupt, A.D., Barron, A.E., \& Kemker, K. (2008). Examining the digital divide in K-12 public schools: Four-year trends for supporting ICT literacy in Florida. Computers \& Education, 51(4), 1648-1663. Retrieved from https://doi.org/10.1016/j.compedu.2008.04.002.

NAGB. (2014). 2014 Abridged Technology and Engineering Literacy framework for the 2014 National Assessment of Educational Progress. Washington, DC: National Assessment Governing Board. Retrieved from https://files.eric.ed.gov/fulltext/ED563941.pdf.

Vuorikari, R., Punie, Y., Carretero Gomez, S., \& van den Brande, G. (2016). DigComp 2.0: The digital competence framework for citizens. Update phase 1: The conceptual reference model. Joint Research Centre Report EUR 27948 EN. Luxembourg: Publication Office of the European Union. Retrieved from https://doi.org/10.2791/11517.

Open Access This chapter is licensed under the terms of the Creative Commons Attribution-NonCommercial 4.0 International License (http://creativecommons.org/licenses/by-nc/4.0/), which permits any noncommercial use, sharing, adaptation, distribution and reproduction in any medium or format, as long as you give appropriate credit to the original author(s) and the source, provide a link to the Creative Commons license and indicate if changes were made.

The images or other third party material in this chapter are included in the chapter's Creative Commons license, unless indicated otherwise in a credit line to the material. If material is not included in the chapter's Creative Commons license and your intended use is not permitted by statutory regulation or exceeds the permitted use, you will need to obtain permission directly from the copyright holder. 